\title{
Childhood Cancer Survivors and Distance Education Challenges: Lessons Learned from the COVID19 Pandemic
}

\author{
Lisa Carey $^{1}$, Kathy Ruble ${ }^{2}$, Juliana Pare-Blagoev ${ }^{3}$, Kimberly Milla ${ }^{1}$, Clifton Thornton ${ }^{4}$, \\ Sydney Henegan ${ }^{4}$, and Lisa Jacobson ${ }^{1}$ \\ ${ }^{1}$ Kennedy Krieger Institute \\ ${ }^{2}$ Johns Hopkins Hospital \\ ${ }^{3}$ Johns Hopkins University School of Education \\ ${ }^{4}$ Johns Hopkins University School of Nursing
}

December 23, 2020

\begin{abstract}
Background: Pediatric cancer patients and survivors have historically struggled to receive adequate educational supports. In the Spring of 2020, the COVID19 pandemic forced an emergency switch from traditional in-person education models to distance education. Methods: The current study presents initial data from a quality improvement project which included a round of qualitative interviews conducted with parents of pediatric oncology patients at risk for educationally-relevant neurocognitive impacts of disease or treatment. The focus of the interviews was patient experiences of education and instructional delivery during the COVID19 school closures in Spring of 2020 and the beginning of the 2020-2021 school year; interviews were conducted via videoconference and transcripts were analyzed using a phenomenological approach. Results: Three emergent themes were found regarding the shared experiences of distance schooling for children with cancer during the COVID19 school closures: 1) attention, 2) mental health, and 3) access to instruction. This study describes and explores each theme and offers suggestions for changes to provider service delivery as a result of new pandemic-related schooling needs.
\end{abstract}

\section{Hosted file}

PCORI_qual paper final 12-21.pdf available at https://authorea.com/users/384578/articles/ 500144-childhood-cancer-survivors-and-distance-education-challenges-lessons-learnedfrom-the-covid19-pandemic

\section{Hosted file}

covid paper table.pdf available at https://authorea.com/users/384578/articles/500144childhood-cancer-survivors-and-distance-education-challenges-lessons-learned-from-thecovid19-pandemic 